\title{
Linguistic and Cultural Characteristics of Russian Political Blogosphere
}

\author{
Olga Maximova \\ Department of Foreign Languages \\ Faculty of Humanities and Social Sciences \\ Peoples' Friendship University of Russia \\ Moscow, Russia \\ E-mail: maximova_ob@pfur.ru
}

\author{
Maia Egorova \\ Department of Foreign Languages \\ Faculty of Humanities and Social Sciences \\ Peoples' Friendship University of Russia \\ Moscow, Russia \\ E-mail: egorova_ma@pfur.ru
}

\begin{abstract}
The article provides an analysis of linguistic and cultural specificity of the Internet political discourse. The significant characteristics of the Russian blogosphere are highlighted. An attempt is made to reveal the semantic dominants of bloggers' discourse. The authors come to the conclusion that cultural specificity is a broad category which can be described as a combination of factors defining the essential features of society's culture.
\end{abstract}

Keywords - cultural specificity; level of culturological context; precedent text; intercultural interaction; the Internet; blogosphere

\section{INTRODUCTION}

The globalization of all spheres of the public life, stimulating intensive intercultural interaction and being synchronized with the development of new communication technologies has led to an increased scientific interest in the network discourse of the linguists who identify features of the Internet language [1], of the specialists in the sphere of computer-mediated communication $[3 ; 4]$ and discourse analysis [5] who study various Internet communication effects, new forms and potential of the political communication which has not been yet exposed to a full extent [2].

The chosen theme is at the intersection of the abovementioned focuses of scientific research which are closely interconnected. We sought to find a method of Internet texts analysis, which would allow us to show in a most contrasting way the interaction of languages and cultures that are deployed in the sphere of electronic communication. Our choice of political discourse as the material for the study was due to the fact that it is in this sphere that cross-cultural interaction can manifest itself most sharply. In addition, the analysis of political blogs on the subject of their linguocultural specificity is challenging in the way that political bloggers are rather interested in the accuracy of the appeal to the cultural type of their audience: it is important to communicate with the audience in the understandable and convincing manner, therefore the usage of culturally-specific units is connected with this task.
Among other things, we were interested in the possible effect of the fact that all the major structural elements of the Internet communication have been created by the representatives of the English-speaking culture and were also oriented to them. Thus, the freedom (convenience) of expression, which the Internet communication implies, may be better for English-speaking users, for example, than for the Russian-speaking ones, forced either to use the opportunities of electronic communication not so fully and freely, or to sacrifice some of their habits of verbal expression.

In addition, we sought to find the signs of the "clicking culture or digital culture" - a new mentality which is connected with the spread of the Internet [7, p. 115-117] - in the electronic communication. Up to what level is the "new cultural type" represented in the texts, in particular in political blogs? According to what characteristics is it recognized? Do Russian political bloggers align with it? Such questions, doubting linguistic, cultural and even political neutrality of the electronic communication seem to be quite urgent.

\section{The Methodology OF THE STUdy}

In order to identify the specificity of the network linguocultural discourse the analysis of the posts was carried out in the selected Russian-speaking political blogs, which cover the current events of socio-political and public life. In order to select the blogs for our analysis we focused on blogs' popularity ratings, searching by the keywords: "political blogs", "politicians", "top blogs".

The studied materials show that the main feature of the Russian political blogosphere is its extremely high saturation with the elements marked by their cultural specificity. At the same time it was found out that the combination of culturally-significant information, which was contained in the texts of blogs, formed a complex multileveled structure. In this regard, we decided to use for our research the multilevel classification scheme proposed by T.A. Dobrosklonskaya, according to which certain elements of the text may involve cultural context at denotative, connotative, associative and metaphorical levels [6, p. 234]. The application of the multilevel classification seems quite 
relevant for our research due to the following reasons. Firstly, this classification is quite complex: any culturally-specific element of the text can be attributed to one of the levels. Secondly, this classification is not reducible to a simple linear ranking of culturally-specific units; it is more complex and it is multidimensional. This feature seems essential to be applied to online texts, characterized by non-linearity, hypertextuality and openness. The same feature, apparently, can be useful for the study of the texts to reveal the "clicking man" culture, youth subculture and other cultural influences.

\section{RESULTS AND DISCUSSION}

Let us consider the culturally-specific units used in bloggers' communication, depending on the degree of their involvement in the cultural context in the framework of the given multi-level scheme.

The lexical units of the denotative level are represented in the discourse of political blogs, mainly by the proper names. These are the names of the famous politicians, the names of the political parties and the movements, the public institutions, the historical and cultural monuments, etc. Their usage may be explained by the implementation of the information function (for example, mentioning of the names of active politicians)

The second (connotative) level of the cultural context comprises the elements of the political lexicon (mainly political terminology) referring to the universal concepts with different connotations in different cultures and reflecting the specificity of national outlook. Such vocabulary related to the "ideological war" of terms allows the authors to place political and ideological orientations on their own. For example, in covering the events in the Ukraine lexical units with positive, negative and neutral connotations are used and the usage range is extremely broad. Here are some examples: on the one hand - the supporters of the federalization: militia, rebels, separatists, militants, terrorists; on the other hand - the units controlled by Kiev: Maidan self-defense fighters, Ukrainian law enforcers, junta, clique, Bandera underground, punitives.

The next one - the associative - level of the cultural context is represented by the lexical units and phraseology, which are associated in the mentality of culture representatives with certain styles and /or images. These units are used in blogs for expression, evaluation, comparison, or description, for example: "From the United States, Ukraine will receive only the "Maidanian muffin"..." (S.Z. Umalatova's blog). In this example, there is an association with a real event - the distribution of muffins on the Maidan by the Baroness Catherine Ashton.

In addition, the associative level units are used to create a visual, expressive and often ironic characters with evaluative connotations, which express the author's position. For example, the author of the blog expresses his attitude to the activities of Y.V. Tymoshenko as follows: "The fact that Yulia Tymoshenko is guilty before the Ukrainian people, is no doubt. She is a crook, the Ukrainian Gaidar and Chubais in one cocktail"(Vladimir Zhirinovsky's blog). It is obvious that for an adequate understanding of the meaning of the given comparison, the reader should understand what "Chubais" and "Gaidar" symbolize in the mentality of the Russians and what stable associations these names evoke rather than have an accurate idea of the ideological platform and views of E.T. Gaidar and A.B. Chubais.

Regarding the latter, the metaphorical level of the cultural context, it is worth mentioning that it appeared to be actively engaged in the political blogs (for example, in comparison with the mass media texts relating to the news). While for an adequate interpretation of the elements of the associative level it is enough to have a general understanding of a particular event or phenomenon, an appeal to the metaphorical level of the cultural context requires, in addition to the background knowledge, a kind of deep understanding of the meaning of texts that have become the property of the national culture. This fact, in our opinion, causes the high level of the cultural value of the figurative means of the metaphorical level.

Here are some typical examples of the fourth level units usage in bloggers' discourse. In the passage from the post under the headline "Silicone Fruits of the Enlightenment " the title of the play by L.N. Tolstoy is played upon and the attitude to the education reform in modern Russia is expressed: "It turns out that the fruits of modern enlightment, grafted on the root of the "tree" of the State Exam and the Bologna Process, are just some silicone accesssories and shallow mentality of the modern youth" (S.M. Mironov's blog). In the following passage, the author successfully plays upon the names of two Chekhov's plays, drawing parallels between the conflict associated with the Moscow region forests and the lifestyle of the Russian landed gentry: "And the Khimkinskiy forest has been cut down for firewood long ago the same as the Cherry Orchard was and all of Uncles Vanyas of Khimki know about this "(E.V. Limonov's blog).

It is worth noting that culturally significant elements of the associative and metaphorical level, appealing to "the reader's cultural memory" play a dual role in the bloggers' discourse. On the one hand, they allow to express the author's attitude to this or that phenomenon in allegorical or expressive form. On the other hand, their use implies not only the existence of certain background knowledge of the audience, but also active cognitive activity of the reader, recalling the sources to which the text refers. For example, the post devoted to the events in Ukraine involves mythological subjects and characters which are described in the metaphorical context: "Exactly at the place where it was supposed to be the revolution in the Ukraine - it turned to be a chaos <...>. From the foams of this chaos a beautiful Poklonskaya, the Crimea and a lot of interesting things came to us." (E.S. Kholmogorov's blog).

\section{CONCLUSION}

In our analysis we have taken the precedent texts most frequently used in political blogs and identified the elements that refer to the texts of literary works, such as "The War and Peace in Post-Soviet Russia" (I.M. Khakamada's blog), "Cursed Days of Dad" (M.E. Gaidar's blog), "Hello, new Himkinski forest" (E.S. Chirikova's blog); popular songs, for 
example: "Only mountains can be better than the mountains!" (R.A. Kadyrov's blog), "Dzhigurda here, Dzhigurda there" (M.A. Yudenich's blog); movies, cartoons, etc., for example: "The Baba Yaga is against !!!!!!" (D.A. Mitina's blog), "Cheerful summer of 2014" (V.L. Tor's blog), "That's just Star Wars, babies ...." (E.S. Kholmogorov's blog); as well as idioms, proverbs and sayings, cliches, aphorisms, for example: "I am not me, the horse is not mine, and I'm not the driver. I am just a simple driver of the Chevrolet Niva."(V.I. Alksnis's blog).

Our analysis of the precedent texts has revealed a high degree of intertextuality in the blogging discourse that brings blogging closer with the advertising discourse and, in general, can be described as a characteristic feature of the texts of mass communication. It should be noted that the combination of intertextuality and hypertextuality that characterizes the blogging discourse as the phenomenon of the Internet communication, creates a unique combination of the retrospective (the usage of the culturally-specific units helps to perpetuate the existing "old" background knowledge) and perspective (hyperlinks stimulate readers' accumulation of new knowledge).

It is worth paying attention to another feature of the Russian-speaking bloggers' political discourse, namely, the low degree of ethnocentrism which is characteristic for the Russian blogs. In most blogs analyzed by us, in addition to reviewing various aspects of the political life of the country, a great attention is paid to the coverage of foreign policy issues. Such attention reflects the fact that the Russian reader is traditionally focused on obtaining the fullest possible informative picture of the events taking place both in Russia and abroad. Moreover, the information about foreign realities may cause a genuine and sincere interest of the readers, which is sometimes not less than the interest to their own domestic problems.

It should be noted that the low level of ethnocentrism appears in Russian-language blogs not only in organizing and structuring the information, but also at all levels of the cultural context. In contrast, for example, English-speaking bloggers, traditionally use autochthonous culturally-specific lexical units to describe the phenomena and artifacts of another culture, while their Russian counterparts operate with the realities of other cultures (familiar to the Russian readers: quotations from the famous works of foreign literature, films, operas, feathered words and expressions, etc.) with confidence. We would like to mention some relevant examples: "Donbass o muerte" (D.A. Mitina's blog); "Modern, let me put it that way, "Vanity Fair" " (S.M. Mironov's blog); "Navalnyi <...> skillfully creates the image of an anti-corruptionist Robin Hood" (I.M. Khakamada's blog); "Devil's Advocates" (S.Z. Umalatova's blog). It should be noted that the above mentioned examples demonstrate that the authors of the blogs assume that the cultural potential of the audience is quite high.

In addition, the attention should be drawn to such characteristic feature of the blogs as their saturation with lexical units, which reproduces (according to the authors) the specificity of the contemporary Internet cyberculture, for example: "... and I can hardly guess which level of cyberbullying it might be" (M.A. Judenich's blog).

The authors of the blogs deliberately or involuntary "decorate" their discourse with the vocabulary typical of the cyberculture, they adopt the informal patterns of youth Internet communication. Perhaps, there is a focus on the mentality of the "clicking culture", or a sensitive response to the direct linguo-cultural environment which can be found here. Anyway, some kind of culture interference is observed in bloggers' texts. Therefore, it may be assumed that in the process of the analysis of bloggers' texts, cultural-specificity should be interpreted not only in the sense of national specificity, but in general sense, considered as a set of factors that determine the specificity of the culture of a particular society: social, professional, age, etc. Hence, it is possible to identify the elements of various subcultures, characterized by their specific values, stereotypes of behavior and norms, in bloggers' communication. In particular, the Internet represents the culture of Russian humanitarian intelligentsia, the cyberculture of the Internet users as well as youth subculture.

In this context, it is of great interest to study the specificity of bloggers' discourse in the light of the interaction of these subcultures. Focusing on the prospect of a possible solution to this problem, we tried to systematize lexical units, labeled in terms of their "Internet cultural specificity" used by Russian-speaking bloggers, and identified the following semantic dominants:

- words and expressions denoting the participants of computer mediated communication (e.g., bloggers, friends, trolls, LJ users, network armchair warriors);

- words and expressions denoting the realities of the "network everyday routine" (e.g., Google, Facebook, friends' list, blogosphere, Twitter);

- words and expressions denoting network communication and human-computer interaction (e.g., to ban, to unfriend, to post, to click, Googling);

- words and phrases denoting the courtesy formulae typical for network communication, stereotypical comments, standard forms of address when communicating in blogs (e.g., +1 ( "completely agree"), PS typed in Cyrillic alphabet (from Latin "post-scriprum”));

- elements of Internet slang and youth jargon, often written with a conscious deviation from the spelling rules.

It seems obvious that these "inclusions" of computer discourse elements, apart from their denotative role, fulfill both the emotional and expressive functions and contain evaluation components; therefore, it is possible to refer to the multilevel character of "Internet culture", "youth culture", etc. involved into the texts of political blogs. 


\section{REFERENCES}

[1] Crystal D. (2001). Language and the Internet. Cambridge: Cambridge University Press, 2001, 272 p. ISBN 051101340 X; ISBN 0521 802121.

[2] Dahlgren P. (2005). The Internet, Public Spheres, and Political Communication: Dispersion and Deliberation. Political Communication No 20 (22). 147-162, $2005 . \quad$ DOI: 10.1080/10584600590933160

[3] Herring S. C., Scheidt L. A., Bonus S., and Wright E. (2005) Weblogs as a bridging genre. Information, Technology and People No 2 (18). 142-171.

[4] Herring S. C., Kouper I., Paolillo J. C., Scheidt L. A., Tyworth M., Welsch P., Wright E., and Yu N. (2005). Conversations in the blogosphere: An analysis "from the bottom up". Proceedings of the Thirty-Eighth Hawaii International Conference on System Sciences (HICSS-38). Los Alamitos: IEEE Press. http://ella.slis.indiana.edu/ herring/blogconv.pdf

[5] Hodge B. (2014). Critical electronic discourse analysis : social and cultural research in the electronic age. Innovative Methods and Technologies for Electronic Discours Analysis, H. L. Lim and F. Sudweeks, Eds. 191- 209. DOI:10.4018/978-1-4666-4426-7.ch009

[6] Dobrosklonskaya T.G. (2008). Medialinguistics: The system approach to the study of mass communicaton language (the contemporary British media discourse). Moscow, Flinta: Nauka, 264 p. ISBN 978-5-9765-0273-4, 978-5-02-034806-6.

[7] Tarasenko V. N. (2000). The anthropology of the Internet: selforganization of the "clicking man". Social Sciences and Contemporaneity No 5. 111-120.

[8] Alksnis V.I. URL : http://v-alksnis2.livejournal.com/207969.html (last accessed date: 09.10.2016).

[9] Chirikova E.S. URL : http://jenya-khimles.livejournal.com (last accessed date: 09.10.2016).

[10] Gaidar M.E. URL : http://m-gaidar.livejournal.com (last accessed date: 09.10.2016)

[11] Kadyrov R.A. URL :http://ya-kadyrov.livejournal.com (last accessed date: 09.10.2016)

[12] Khakamada I.M. URL: http://hakamada.ru/Statement/1451/1551.html (last accessed date: 09.10.2016).

[13] Kholomogorov E.S. URL: http://holmogor.livejournal.com/6422683.html (last accessed date: 09.10.2016).

[14] Limonov E.V. URL: http://limonoveduard.livejournal.com/258149. html ?page $=3$ (last accessed date: 09.10.2016).

[15] Mironov S.M. URL : http://sergeymironov.livejournal.com/293887.html (last accessed date: 09.10.2016).

[16] Mitina D.A. URL: http://kolobok1973.ru/archives/51593 (last accessed date: 09.10.2016).

[17] Tor V.L. URL : http://tor85.livejournal.com (last accessed date: 09.10.2016).

[18] Umalatova S.Z. URL: http://sajiumalatova.livejournal.com/44313.html (last accessed date: 09.10.2016).

[19] Yudenich M.A. URL : http://marina-yudenich.livejournal.com (last accessed date: 09.10.2016).

[20] Zhirinovsky V.V. URL http://zhirinovski.livejournal.com/15400.html (last accessed date: 09.10.2016). 